\title{
A chorus of disapproval
}

\author{
The fight against AIDS is losing ground, but the current spate of mud-slinging is far from helpful.
}

\lceil he global conversation about AIDS is beginning to sound like a high-decibel exercise in finger-pointing and blame. This dangerous trend should be on the minds of the thousands of attendees convening in Mexico City this weekend for the XVII International AIDS Conference.

Thirty-three million people around the world are HIV-positive, and more than 6,800 become infected every day. Tests on microbicides and vaccines have failed, and have put some volunteers at greater risk of HIV infection. Yet critics are attacking the very programmes and people trying to solve these problems, with some even calling for an end to government spending on the search for a vaccine.

This is an overreaction. As many scientists point out, the search for a malaria vaccine has seen dozens of failed trials, whereas only three AIDS vaccines have so far been tested in efficacy studies. What is needed are better vaccine candidates to test, so it makes sense that the major backers of HIV vaccine trials, including the US National Institutes of Health, are now focusing on the basic research that could help the field move forward (see page 565).

Meanwhile, two books published last year claim that the United Nations AIDS programme, UNAIDS, has led an ineffective, politically motivated response to the disease and has distorted statistics in an effort to garner more money (see Nature 447, 531-532; 2007). And critics such as Roger England, who runs a small think tank in Grenada, argue that spending on AIDS has distorted poor countries' priorities and weakened their health systems. England proposes that UNAIDS be shut down, and the money spent on AIDS programmes shifted to general funding for health systems. Amid the debate on these questions, the founding director of UNAIDS, Peter Piot, announced in April that he would step down at the end of this year, throwing the agency into uncertainty at a crucial time.

There is no doubt that many poor countries' health systems are struggling, but it is wrong to say that AIDS aid is responsible. In fact, AIDS programmes have shown how poor countries can use new models to deliver needed care, for instance by providing antiretroviral treatments effectively, putting to rest claims that the costly drugs could not be used correctly outside resource-rich nations.
It is also wrong to assume that governments will spend money effectively to fight AIDS if given funds to support health systems overall, as England suggests. Today, many strategies for delivering AIDS treatment target groups such as women, homosexuals and intravenous drug users that have been ignored by governments in the past - neglect that fuelled the spread of the disease. More money should be spent on both AIDS and strengthening health-care systems. And this will be possible if donor governments live up to their prom-
"More money should be spent on both AIDS and strengthening health-care systems." ises, such as the pledges of general and disease-specific aid to Africa that were repeated this July at the G8 meeting in Japan.

On that front, it is heartening that the US House and Senate have reauthorized $\$ 48$ billion for the President's Emergency Plan for AIDS Relief ( $\$ 9$ billion of which is for fighting malaria and tuberculosis). If President Bush signs the bill as expected, the programme will also permit the US government to reverse the shameful and embarrassing policy that bans travellers with HIV from entering the country. That might serve as an example to other governments that still sanction discrimination against those who are HIV-positive.

The world is still far from achieving the goal adopted in 2000 by UN member states, which pledged to provide universal access to AIDS treatment by 2010. Three million people now receive lifesaving antiretroviral drugs, but $70 \%$ of those in low- to middleincome countries who need them don't get them. Indeed, the example of wealthy nations themselves shows what happens when they lose focus on AIDS. In the United States, for instance, reports now indicate that HIV infection rates have begun to rise in Latinos and young gay men.

The activists and scientists about to meet in Mexico City must demand that leaders keep their eye on the ball. The world now has models for providing treatment and care in the places that sorely need it, and is in a position to make more tangible gains against AIDS. This is no time to backslide, and the Mexico City meeting must deliver this message loud and clear.

\section{The greener grid}

\section{Governments need to back an overhaul to get the electricity grid ready for renewable energy.}

n 17 July, former US vice-president Al Gore proposed that the United States should commit to producing 100\% of its electricity from renewable energy and truly clean carbon-free sources within ten years. That is an ambitious and optimistic plan, to put it mildly. But whether or not the United States achieves Gore's goal, the country is already expanding its generation portfolio to include renewable sources of electricity, such as solar, wind and geothermal, and could do so much faster with a better regulatory and incentive system. Successful examples of the latter can be found in Germany, where 'feed-in tariffs' offer end-users a guaranteed price for selling renewable electricity back to the grid (see page 558).

True, these shifts towards greener sources of electricity can have side effects that are not so green. A case in point is Texas, whose famous winds are now producing more than 5,300 megawatts, by far the largest installed wind-turbine capacity in the United States. 